\title{
PERANCANGAN TEKNOLOGI SEDERHANA UNTUK MEMBANGKITKAN MICROWAVE PLASMA DALAM CAIRAN
}

\author{
Muh. Firdan Nurdin ${ }^{1}$, Andi Erwin Eka Putra ${ }^{2}$, Novriany Amaliyah ${ }^{3}$ \\ ${ }^{1}$ Jurusan Teknik Mesin, Universitas Borneo Tarakan, Tarakan, Indonesia \\ ${ }^{2}$ Departemen Teknik Mesin, Universitas Hasanuddin, Makassar, Indonesia \\ 1 firdandborneo.ac.id \\ 2erwinep@eng.unhas.ac.id \\ 3amaliyah nophiedyahoo.com
}

\begin{abstract}
Plasma technology has interested, especially plasma in liquid which can be applied in the process of gas productions, water treatment, and nanomaterial productions. The purpose of this study is to make a simple technology 2.45 $\mathrm{GHz}$ microwave plasma and generate in the variation of liquids such as distilled water, seawater and $X$-Ray liquid waste by utilizing a microwave oven, as well as to observe the effect of vacuum pressure variations. A microwave oven was modified by integrating a waveguide and a plasma reactor for plasma observation. The results, plasma was generated in distilled water at a vacuum pressure of about $7 \mathrm{kPa}, X$-Ray liquid waste at a vacuum pressure of about $13 \mathrm{kPa}$, and seawater at a vacuum pressure of about $34 \mathrm{kPa}$.
\end{abstract}

Keywords-2.45 GHz Microwave, Plasma in-Liquid, Plasma Reactor, Waveguide

Intisari-Teknologi plasma telah menarik banyak perhatian terutama plasma dalam cairan yang mana dapat diaplikasikan dalam proses produksi gas, water-treatment, dan produksi nano material. Penelitian ini bertujuan untuk membuat alat pembangkit sederhana $2,45 \mathrm{GHz}$ Microwave Plasma dan membangkitkannya dalam berbagai cairan yakni air destilasi, limbah cairan X-Ray dan air laut, serta melakukan observasi pengaruh variasi tekanan vakum terhadap plasma. Microwave oven dimodifikasi dengan mengintegrasikan pengarah gelombang (waveguide) dan reaktor plasma untuk memudahkan observasi fenomena plasma. Hasil dari penelitian ini, plasma telah dibangkitkan dalam cairan air mineral pada tekanan vakum sebesar 7 $\mathrm{kPa}$, limbah cairan X-Ray pada tekanan $13 \mathrm{kPa}$ dan air laut pada tekanan vakum $34 \mathrm{kPa}$.

Kata Kunci-2,45 GHz Microwave, Plasma Dalam Cairan, Reaktor Plasma, Waveguide.

\section{PENDAHULUAN}

Saat ini teknologi plasma telah menarik banyak perhatian. Teknologi ini dapat diaplikasikan secara luas utamanya pada teknologi rekayasa material seperti nanomaterial, Diamond like carbon (DLC), dan material komposit, pengolahan limbah berbahaya seperti cairan medis, dan sintesis air laut menjadi material berguna, serta produksi gas dari hidrokarbon cair [1]-[5]. Plasma dikenal juga sebagai materi fase ke empat setelah fase padat, cair dan gas dimana partikel gas terionisasi. Ionisasi merupakan proses terlepasnya elektron suatu atom atau molekul dari ikatannya. Proses ionisasi dapat dicapai melalui energi pemanasan yang tinggi, high- voltage dan gelombang mikro [6]. Akibat dari sumber energi tersebut, molekul gas menjadi lebih aktif dan akan berada pada fase plasma. Pada fase plasma, partikelpartikel bergerak bebas termasuk beberapa elektron dan ion yang bermuatan positif yang mana akan bertumbukkan sehingga menimbulkan pancaran foton. Pancaran foton inilah yang merupakan salah satu karakteristik dari plasma [7].

Umumnya, energi high-voltage, dan radiasi gelombang elektromagnetik berupa RF (Radio Frekuensi) $13,56 \mathrm{MHz}$ dan gelombang mikro (microwave) $2,45 \mathrm{GHz}$ digunakan sebagai sumber energi untuk membangkitkan plasma [8]. Gelombang elektromagnetik emiliki kelebihan yakni konsumsi energi yang lebih rendah untuk membangkitkan plasma dibandingkan high-voltage. Gelombang mikro dengan frekuensi $2,45 \mathrm{GHz}$ dapat ditemukan dalam Oven microwave yang biasanya digunakan untuk proses pemanasan makanan. Gelombang mikro tersebut diubah menjadi energi termal yang mana akan dimanfaatkan untuk menghasilkan proses ionisasi dengan menambahkan waveguide dan reaktor plasma.

Beberapa penelitian dalam proses pembangkitan plasma telah dilakukan yakni pembangkitan plasma pada tekanan 1 atmosfer, produksi hidrogen dari bioetanol dan metana klatrat (methane hydrate), produksi nano partikel zinc, dan modifikasi karakteristik material komposit [9][13].

Dari penjelasan di atas, plasma dalam cairan merupakan metode yang sangat penting untuk dikembangkan. Oleh kareana itu, alat pembangkit plasma dalam cairan dirancang dengan memanfaatkan microwave oven rumah tangga yang mudah didapat dan harga terjangkau. Dengan menggunakan alat sederhana ini, pembangkitan plasma dalam cairan diidentifikasi dengan air destilaasi, air laut dan limbah cair X-Ray.

\section{METODE PENELITIAN}

Dalam penelitian ini, bahan yang digunakan adalah Oven Microwave Sanyo tipe EM-S10AS Output Power 400 Watt (Gambar 1) sebagai sumber energi gelombang mikro [14]. Plat aluminium dengan tebal $3 \mathrm{~mm}$ dengan dimensi lebar $100 \mathrm{~mm}$ dan tinggi $100 \mathrm{~mm}$ sebagai waveguide. 


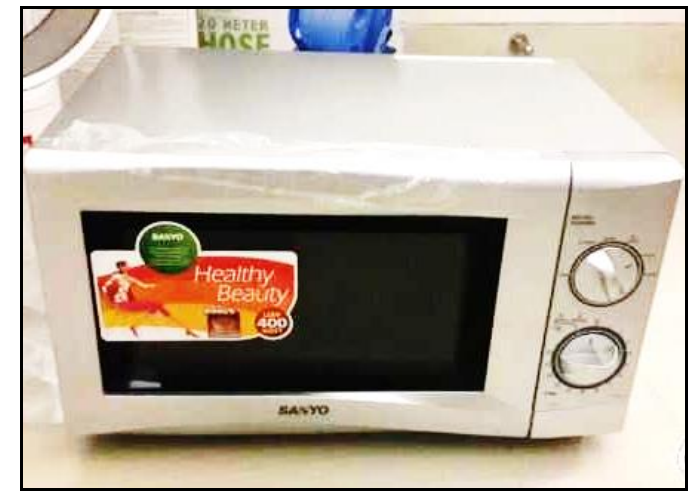

Gambar 1. Oven Microwave Sanyo tipe EM-S10AS Output Power 400 Watt [14].

Bahan reaktor plasma terdiri dari teflon silinder diameter $56 \mathrm{~mm}$ dan $29 \mathrm{~mm}$, Pipa Akrikil diameter 57 $\mathrm{mm}$ dan tinggi $140 \mathrm{~mm}$. Aluminium Silinder dengan diameter $30 \mathrm{~mm}$, elektroda tungsten $3 \mathrm{~mm}$ (2 buah), manifold dan pressure gauge serta O-ring tahan panas yang digunakan sebagai seal reaktor. Jenis cairan yang digunakan dalam pengambilan data yakni air destilasi, limbah cari X-Ray dan air laut dengan volume $100 \mathrm{ml}$, masing-masing.

Pelaksanaan penelitian ini dilakukan dalam beberapa tahap untuk mempermudah dan memperjelas arah penelitian, yaitu tahap perancangan (desain) alat, pembuatan atau perakitan alat, pengujian hasil rancangan, pengamatan, dan pengolahan data seperti disajikan pada Gambar 3.1. Tahap perancangan (desain) alat ini menggunakan program Autodesk Inventor Profesional. Pada perancangan alat pembangkit $2,45 \mathrm{GHz}$ microwave plasma, terlebih dahulu dilakukan 3 tahap pendekatan desain :

\section{Rancangan Fungsional}

Alat ini terdiri dari beberapa komponen utama antara lain: microwave oven yang berfungsi sebagai sumber dari gelombang mikro, pengarah gelombang (waveguide) yang berfungsi sebagai pengarah gelombang mikro) dan reactor yang berfungsi sebagai wadah pengamatan timbulnya plasma.

\section{Rancangan Struktural}

Microwave oven akan dimodifikasi dengan menghilangkan ruang pemanasan (Gambar 2).

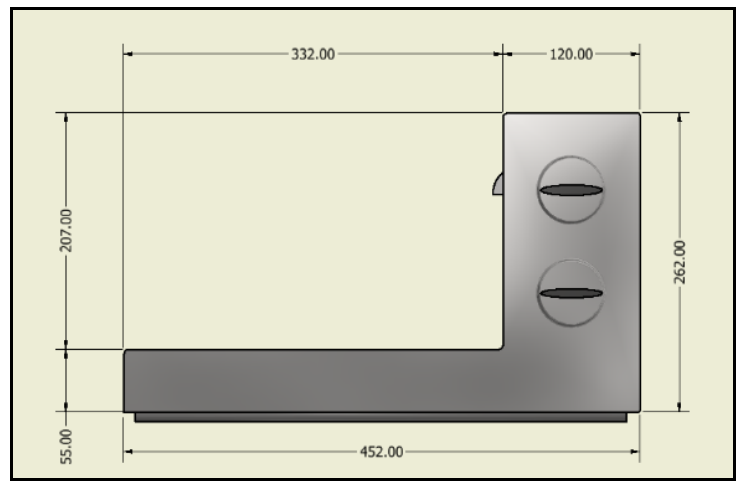

Gambar 2. Rancangan Microwave Oven

Selanjutnya, Waveguide dibuat dari bahan aluminium dengan ukuran lebar $100 \mathrm{~mm}$ dan tinggi $100 \mathrm{~mm}$ dengan panjang $330 \mathrm{~mm}$. Terdapat lubang berdiameter $8 \mathrm{~mm}$ sebagai input elektroda reaktor. Jarak lubang dari magnetron adalah $122 \mathrm{~mm}$ ( $\lambda$ dari frekuensi $2,45 \mathrm{GHz}$ ). Rancangan dapat dilihat pada gambar 3.

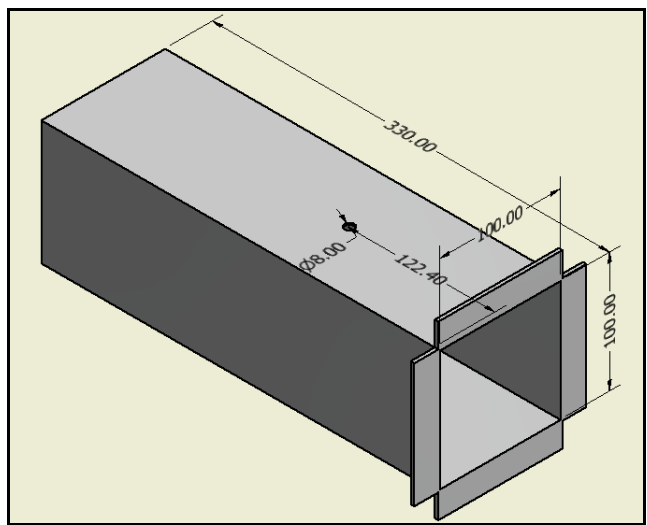

Gambar 3. Rancangan Waveguide

Terakhir, Reaktor Plasma dibuat dari pipa akrilik dengan diameter dalam $55 \mathrm{~mm}$ dan tinggi $140 \mathrm{~mm}$. Penutup atas dan bawah terbuat dari bahan Teflon. O-ring ditempatkan sebagai seal penutup (Gambar 4).

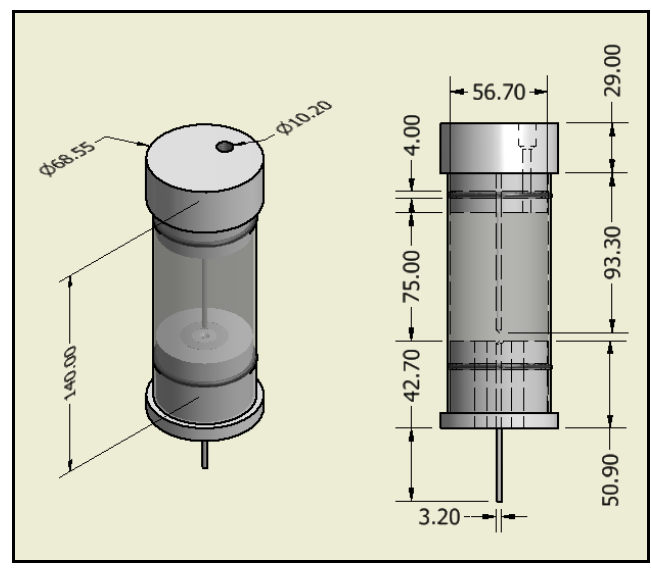

Gambar 4. Rancangan Reaktor Plasma

\section{Rancangan Akhir}

Alat pembangkit 2,45 GHz microwave plasma dirakit dengan menggabungkan ketiga komponen utama tersebut (Gambar 5).

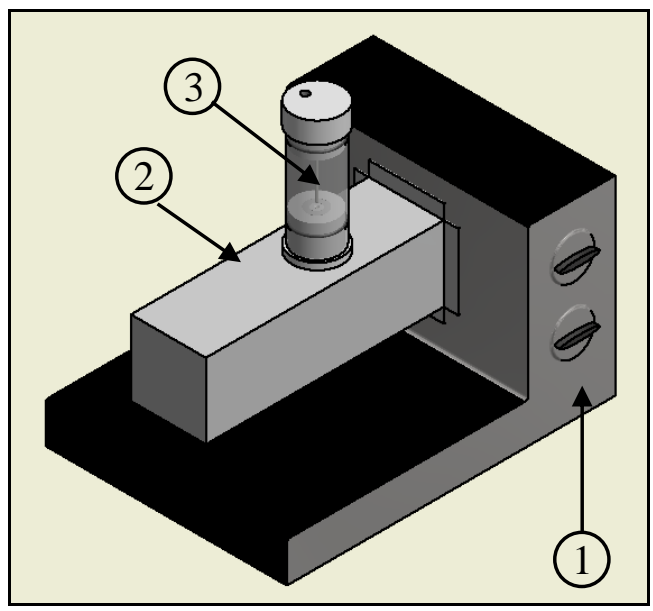

Gambar 5. Rancangan Alat Pembangkit Microwave Plasma 2,45 GHz Microwave Plasma. 
Tabel I

Keterangan Bagian Desain

\begin{tabular}{|c|l|c|}
\hline $\begin{array}{c}\text { No. } \\
\text { Item }\end{array}$ & \multicolumn{1}{|c|}{ Bagian Alat } & Kuantitas \\
\hline 1. & $\begin{array}{l}\text { 2,45 GHz Microwave Energy } \\
\text { Source }\end{array}$ & 1 \\
\hline 2. & Waveguide & 1 \\
\hline 3. & Reaktor Plasma & 1 \\
\hline
\end{tabular}

Setelah perancangan desain selesai, dilanjutkan ke tahap pembuatan atau perakitan alat. Setelah itu, alat diuji coba dengan membangkitkan plasma dalam air destilasi yang mana mempertimbangkan variasi dari dua parameter yakni tekanan dan waktu pembangkitan plasma. Setelah plasma dapat terbangkitkan dalam air destilasi, Selanjutnya dilakukan hal yang sama untuk cairan yang berbeda yakni air laut dan limbah cairan X-Ray. Kemudian dilanjutkan ke tahap pengamatan dan pengolahan data mengenai pembangkitan plasma dalam variasi cairan tersebut.

\section{HASIL DAN PEMBAHASAN}

Pada perancangan alat pembangkit $2.45 \mathrm{GHz}$ microwave plasma, terdapat tiga komponen utama yaitu oven microwave, pengarah gelombang, dan reaktor plasma. Microwave oven akan dimodifikasi dengan mengganti bagian ruang pemanasan dengan pengarah gelombang dngan tujuan untuk mengoptimalkan pnyerapan gelombang mikro oleh elektroda dari reaktor plasma. Pengarah gelombang (waveguide) yang umum digunakan untuk frekuensi $2,45 \mathrm{GHz}$ yakni tipe WG8 dengan jangkauan frekuensi $1,70-2,60 \mathrm{GHz}$ [15]. Kemudian dibuat lubang dengan diameter $8 \mathrm{~mm}$ dan jarak antara lubang terhadap magnetron sekitar $\lambda=122 \mathrm{~mm}$ yang mana merupakan kalkulasi dari panjang satu gelombang pada frekuensi 2,45 GHz. Reaktor plasma dibuat sebagai wadah dari sistem pembangkitan plasma dalam cairan. Reaktor ini terbuat dari bahan akrilik sebagai tabung reaktor dan penutupnya terbuat dari bahan teflon. Ketiga komponen kemudian disatukan sesuai dengan rancangan di Autodesk Inventor sehingga dihasilkan alat sederhana pembangkitan microwave plasma dalam cairan (Gambar 6) dan selanjutnya dilakukan pengujian.

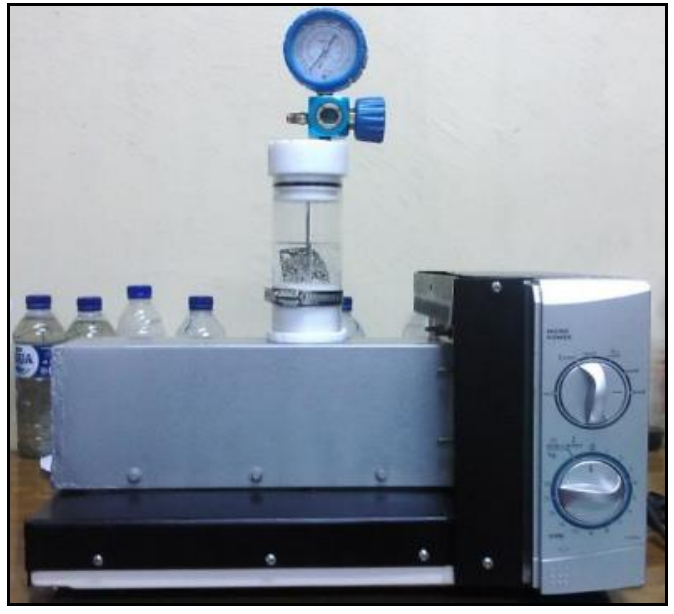

Gambar 6. Alat Microwave Plasma
Pengujian dilakukan dengan power microwave oven sebesar 400 Watt pada tiap tekanan vakum sebesar 95 - 7 $\mathrm{kPa}$ (inkremental $7 \mathrm{kPa}$ ) dengan waktu 2 menit, masingmasing. Plasma dalam cairan dapat dibangkitkan konstan dalam berbagai jenis cairan (Gambar 7), sementara hasil pengolahan data ditabulasikan pada tabel 2 .

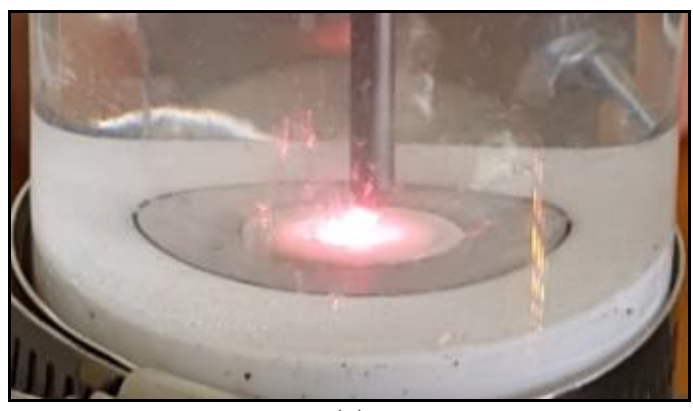

(a)

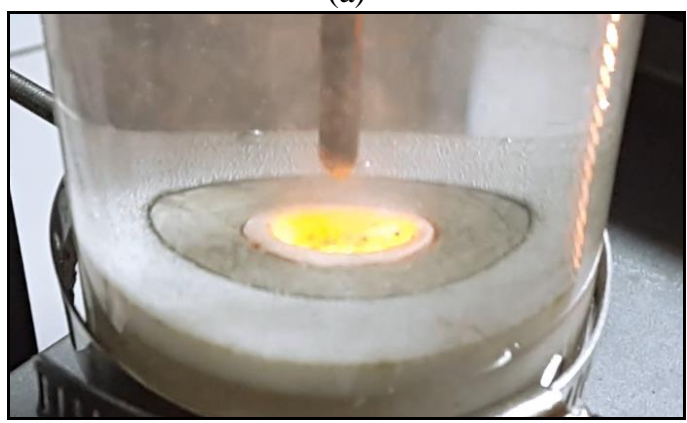

(b)

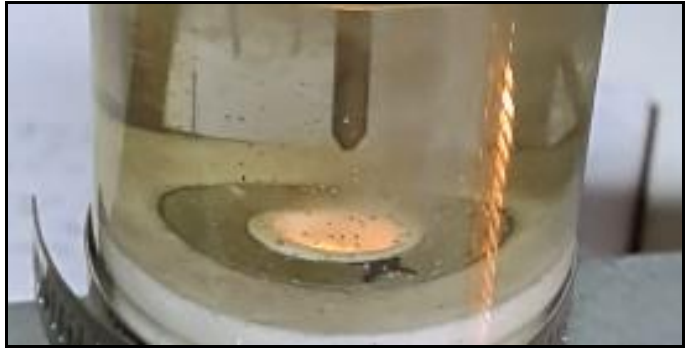

(c)

Gambar 7. Plasma dalam Cairan Air Destilasi (a), Air Laut (c) dan Limbah Cairan X-Ray (c).

Gambar diatas menunjukkan cahaya tampak yang dihasilkan ketika plasma terbangkitkan dalam cairan; air destilasi (a), air laut (b) dan limbah cairan X-Ray (c), masing-masing berbeda. Hal ini dapat dihubungkan dengan komposisi kimia yang terkandung dalam cairan tersebut. S. Horikoshi dan N. Serpone telah menunjukkan hubungan antara emisi cahaya selama proses ionisasi plasma dalam cairan terhadap komposisi kimia. Mereka membuktikannya melalui emisi spektrum dari cahaya tersebut yang mana memperlihatkan unsur gas hidrogen, nitrogen dan oksigen dalam uap air [16], [17]. 
Tabel II

Hasil Pengolahan Data Plasma Dalam Cairan

\begin{tabular}{|c|c|c|c|c|c|c|c|}
\hline \multirow[b]{2}{*}{ No. } & \multirow[b]{2}{*}{$\begin{array}{c}\mathbf{P}_{\text {Vacuum }} \\
(\mathbf{k P a})\end{array}$} & \multicolumn{2}{|c|}{ Air Destilasi } & \multicolumn{2}{|c|}{ Limbah Cair X-Ray } & \multicolumn{2}{|c|}{ Air Laut } \\
\hline & & $\begin{array}{c}\mathbf{t}_{\text {initial generated }} \\
\text { plasma } \\
\text { (detik) }\end{array}$ & Ket & $\begin{array}{l}\mathbf{t}_{\text {initial generated }} \\
\text { plasma (detik) }\end{array}$ & Ket & $\begin{array}{c}\mathbf{t}_{\text {initial generated }} \\
\text { plasma (detik) }\end{array}$ & Ket \\
\hline 1 & 95 & - & Tidak ada & 2 & Gelembung & 2 & Gelembung \\
\hline 2 & 88 & - & Tidak ada & 2 & Gelembung & 2 & Gelembung \\
\hline 3 & 81 & - & Tidak ada & 1 & $\begin{array}{l}\text { Plasma } \\
\text { diskontinyu }\end{array}$ & 2 & Gelembung \\
\hline 4 & 74 & - & Tidak ada & 1 & $\begin{array}{l}\text { Plasma } \\
\text { diskontinyu }\end{array}$ & 2 & $\begin{array}{l}\text { Plasma } \\
\text { diskontinyu }\end{array}$ \\
\hline 5 & 68 & - & Tidak ada & 1 & $\begin{array}{l}\text { Plasma } \\
\text { diskontinyu }\end{array}$ & 2 & $\begin{array}{l}\text { Plasma } \\
\text { diskontinyu }\end{array}$ \\
\hline 6 & 61 & - & Tidak ada & 1 & $\begin{array}{l}\text { Plasma } \\
\text { diskontinyu }\end{array}$ & 2 & $\begin{array}{l}\text { Plasma } \\
\text { diskontinyu }\end{array}$ \\
\hline 7 & 54 & - & Tidak ada & 1 & $\begin{array}{l}\text { Plasma } \\
\text { diskontinyu }\end{array}$ & 2 & $\begin{array}{l}\text { Plasma } \\
\text { diskontinyu }\end{array}$ \\
\hline 8 & 47 & 30 & Gelembung & 1 & $\begin{array}{l}\text { Plasma } \\
\text { diskontinyu }\end{array}$ & 2 & $\begin{array}{l}\text { Plasma } \\
\text { diskontinyu }\end{array}$ \\
\hline 9 & 40 & 25 & Gelembung & 1 & $\begin{array}{l}\text { Plasma } \\
\text { diskontinyu }\end{array}$ & 2 & $\begin{array}{l}\text { Plasma } \\
\text { diskontinyu }\end{array}$ \\
\hline 10 & 34 & 25 & Gelembung & 1 & $\begin{array}{l}\text { Plasma } \\
\text { konstan }\end{array}$ & 2 & $\begin{array}{l}\text { Plasma } \\
\text { diskontinyu }\end{array}$ \\
\hline 11 & 27 & 23 & $\begin{array}{l}\text { Plasma } \\
\text { diskontinyu }\end{array}$ & 1 & $\begin{array}{l}\text { Plasma } \\
\text { konstan }\end{array}$ & 2 & $\begin{array}{l}\text { Plasma } \\
\text { diskontinyu }\end{array}$ \\
\hline 12 & 20 & 5 & $\begin{array}{l}\text { Plasma } \\
\text { diskontinyu }\end{array}$ & 1 & $\begin{array}{l}\text { Plasma } \\
\text { konstan }\end{array}$ & 2 & $\begin{array}{l}\text { Plasma } \\
\text { diskontinyu }\end{array}$ \\
\hline 13 & 13 & 4 & $\begin{array}{l}\text { Plasma } \\
\text { diskontinyu }\end{array}$ & 1 & $\begin{array}{l}\text { Plasma } \\
\text { konstan }\end{array}$ & 1 & $\begin{array}{l}\text { Plasma } \\
\text { konstan }\end{array}$ \\
\hline 14 & 7 & 3 & $\begin{array}{l}\text { Plasma } \\
\text { konstan }\end{array}$ & 1 & $\begin{array}{l}\text { Plasma } \\
\text { konstan }\end{array}$ & 1 & $\begin{array}{l}\text { Plasma } \\
\text { konstan }\end{array}$ \\
\hline
\end{tabular}

Berdasarkan tabel II, plasma terbangkitkan dalam air destilasi, air laut dan limbah cairan rongten pada tekanan vakum $27 \mathrm{kPa}-7 \mathrm{kPa}, 88 \mathrm{kPa}-7 \mathrm{kPa}$, dan $74 \mathrm{kPa}-7$ $\mathrm{kPa}$, masing-masing. Dari ketiga jenis cairan tersebut, air laut merupakan carian yang mana plasma dapat terbangkitkan konstan lebih mudah pada tekanan $34 \mathrm{kPa}$, sedangkan untuk air destilasi dan limbah rongten pada tekanan $7 \mathrm{kPa}$. Plasma terbangkitkan konstan, diindikasikan dengan intensitas terbentuknya gelembung yang sangat tinggi shingga proses ionisasi pun konstan. Sementara waktu awal terbangkitnya plasma rata-rata sekitar 2 detik untuk ketiga jenis cairan tersebut.

Sebelum plasma terbangkitkan dalam ketiga jenis cairan tersebut, karakteristik awal ditandai dengan munculnya gelembung yang mana merupakan proses perubahan fase cair menjadi gas. Kemudian gas tersebut selanjutnya akan terionisasi dan kemudian plasma terbangkitkan. Namun pada tekanan $13 \mathrm{kPa}, 40 \mathrm{kPa}$ dan $54 \mathrm{kPa}$ untuk masing-masing ketiga jenis cairan tersebut, plasma terbangkitkan secara diskontinyu. Karakteristik plasma diskontinyu dapat kita simpulkan sebagai fase transisi yang merupakan fase yang terjadi antara fase gelembung dan fase plasma konstan.

Dari penjelasan tabel di atas, dapat kita jelaskan bahwa pembangkitan plasma merupakan fungsi dari tekanan dimana semakin rendah tekanan (tekanan vakum semakin besar) maka waktu yang dibutuhkan untuk membangkitkan plasma dalam cairan akan semakin cepat. Pengaruh tekanan vakum terhadap pembangkitan plasma dapat dihubungkan dengan fungsi tekanan terhadap suhu yakni titik didih. Seperti yang kita ketahui bahwa semakin rendah tekanan atmosfir, maka semakin rendah titik didih zat cair tersebut. Akibat titik didih zat cair rendah, maka suhu panas laten akan semakin rendah pula shingga proses ionisasi pun lebih cepat terjadi dan plasma lebih cepat terbangkitkan.

Sesuai dengan penjelasan data di atas, maka tekanan vakum sebesar $7 \mathrm{kPa}$ dijadikan sebagai acuan awal yang mana merupakan tehnik untuk membangkitkan plasma dalam cairan air destilasi pada tekanan 1 atm $(101,3 \mathrm{kPa})$. Tehnik tersebut dilakukan dengan cara menurunkan tekanan sampai pada tekanan dimana plasma terbangkitkan konstan $(7 \mathrm{kPa})$. Setelah plasma terbangkitkan, tekanan vakum $7 \mathrm{kPa}$ akan meningkat hingga mencapai tekanan $1 \mathrm{~atm}$ selama beberapa waktu. Kenaikan tekanan tersebut merupakan akibat dari proses ionisasi plasma pada sistem reaktor tertutup. Hasilnya, plasma dapat dibangkitkan di dalam cairan pada tekanan 1 atm dengan waktu yang dibutuhkan 9.43 menit. Pengujian pembangkitan plasma dalam air destilasi pada tekanan 1 atm dilakukan sebagai dasar acuan untuk produksi gas dari cairan.

Dalam penelitian ini, dilakukan kalibrasi energi microwave yang terabsorbsi ke dalam reaktor dengan metode kalorimetrik [7]. Metode ini merupakan dasar 
untuk mengkonversi energi microwave ke bentuk energi panas. Energi microwave dikalkulasi melalui panas yang dihasilkan dalam air. Energi yang terserap dalam air dan diasumsikan sebagai energi microwave $P m w=P$ water load dimana dapat dilihat pada persamaan sebagai berikut:

$$
P_{m w}=P_{\text {water load }}=\frac{\left(m_{W} \cdot c_{W}+m_{c} \cdot c_{c}\right)\left(T_{f}-T_{i}\right)}{t}(1)
$$

Dimana, massa air $\left(m_{w}\right)$, panas spesifik air $\left(c_{w}\right)$, massa penampung air $\left(m_{c}\right)$, panas spesifik penampung air $\left(c_{c}\right)$, suhu awal dan suhu akhir air $\left(T_{i}, T_{f}\right)$, dan waktu selama air terkena radiasi microwave $(t)$. Dengan persamaan ini, maka dapat dihitung energi microwave pada panjang gelombang sebesar $122 \mathrm{~mm}$ dari titik magnetron (lubang pada waveguide) dan berikut beberapa parameter yang diperoleh:

\begin{tabular}{|c|c|c|}
\hline$m_{w}$ & $=1$ & gram \\
\hline$m_{c}$ & $=0,5$ & gram \\
\hline$c_{w}$ & $=1$ & $\mathrm{kal} / \mathrm{gr}^{\circ} \mathrm{C}$ \\
\hline$c_{c}$ & $=0,2$ & $\mathrm{kal} / \mathrm{gr}^{\circ} \mathrm{C}$ \\
\hline$T_{i}$ & $=30$ & ${ }^{\circ} \mathrm{C}$ \\
\hline$T_{f}$ & $=54$ & ${ }^{\circ} \mathrm{C}$ \\
\hline$t$ & 20 & sekon \\
\hline
\end{tabular}

maka, energi yang diserap pada air adalah

$P_{m w}=\frac{(1 \times 1+0,5 \times 0,2)(54-30)}{20}$

$P_{m w}=\frac{(1+0,1)(24)}{20}$

$P_{m w}=1 \mathrm{kal} / \mathrm{s}=4,6 \mathrm{watt}$

Berdasarkan hasil di atas, dapat diasumsikan bahwa jumlah energi yang terabsorbsi ke elektroda untuk membangkitkan plasma dalam cairan sebesar 4,6 Watt. Jumlah energi tersebut hanya $1 \%$ dari jumlah energi output magnetron sebesar 400 Watt. Oleh karena itu, dibutuhkan pengembangan lebih lanjut untuk mengotimalkan energi output magnetron.

\section{IV.KESIMPULAN}

Alat pembangkit $2,45 \mathrm{GHz}$ microwave plasma ini terdiri dari 3 komponen utama yakni microwave oven 400 watt, pengarah gelombang WG8 dan reaktor plasma kapasitas $342 \mathrm{ml}$. Pengujian alat pembangkit 2,45 GHz microwave plasma dapat membangkitkan plasma secara konstan dalam cairan air destilasi, air laut dan limbah cair X-Ray pada kondisi tekanan vakum sebesar $7 \mathrm{kPa}$. Variasi tekanan vakum sangat mempengaruhi waktu yang dibutuhkan untuk membangkitkan plasma dimana semakin besar tekanan vakumnya (semakin kecil tekanan) maka semakin cepat waktu yang dibutuhkan untuk membangkitkan plasma. Untuk tekanan 1 atm, pembangkitan plasma dalam air destilasi membutuhkan waktu 9.43 menit. Adapun tujuan dibangkitkannya plasma dalam cairan adalah sebagai dasar acuan untuk memproduksi energi gas dari cairan dan nanomaterial.

\section{UCAPAN TERIMA KASIH}

Terima kasih disampaikan kepada Universitas Borneo Tarakan yang telah memberikan bantuan dana DIPA dalam penelitian ini.

\section{REFERENSI}

[1] S. Nomura et al., "Discharge characteristics of microwave and high-frequency in-liquid plasma in water," Appl. Phys. Express, vol. 1, no. 4, pp. 0460021-0460023, 2008, doi: 10.1143/APEX.1.046002.

[2] A. F. Yong Yang, Young I. Cho, Plasma Discharge in Liquid: Water Treatment and Applications. 2012.

[3] G. Saito and T. Akiyama, "Nanomaterial Synthesis Using Plasma Generation in Liquid," J. Nanomater., vol. 2015, 2015, doi: 10.1155/2015/123696.

[4] S. Horikoshi and N. Serpone, "In-liquid plasma: A novel tool in the fabrication of nanomaterials and in the treatment of wastewaters," RSC Adv., vol. 7, no. 75, pp. 47196-47218, 2017, doi: 10.1039/c7ra09600c.

[5] A. Varade, A. Krishna, K. N. Reddy, M. Chellamalai, and P. V. Shashikumar, "Diamond-like Carbon Coating Made by RF Plasma Enhanced Chemical Vapour Deposition for Protective Antireflective Coatings on Germanium," Procedia Mater. Sci., vol. 5, pp. 1015-1019, 2014, doi: 10.1016/j.mspro.2014.07.390.

[6] M. Nur, Plasma Physics and Aplications. 2011.

[7] Y. Yang, Y. I. Cho, and A. Fridman, "Plasma Discharge in Water and Its Application for Industrial Cooling Water Treatment," no. June, p. 30, 2011, [Online]. Available: https://studylib.net/doc/18261981/plasma-discharge-inwater-and-its-application-for.

[8] F. F. Chen, "Radiofrequency Plasma Sources for Semiconductor Processing," Adv. Plasma Technol., pp. 99-115, 2008, doi: 10.1002/9783527622184.ch6.

[9] A. Ryane, A. Oktiawan, W. Syakur, "Penggunaan Teknologi Plasma Dalam Mengurangi Kandungan BOD Pada Limbah Minuman Ringan," pp. 1-6, 2013.

[10] N. Amaliyah, S. Mukasa, S. Nomura, H. Toyota, and T. Kitamae, "Plasma in-liquid method for reduction of zinc oxide in zinc nanoparticle synthesis," Mater. Res. Express, vol. 2, no. 2, p. 25004, 2015, doi: 10.1088/2053$1591 / 2 / 2 / 025004$

[11] C. Chaichumporn, P. Ngamsirijit, N. Boonklin, K. Eaiprasetsak, and M. Fuangfoong, "Design and Construction of $2.45 \mathrm{GHz}$ Microwave Plasma Source at Atmospheric Pressure," vol. 8, pp. 94-100, 2011, doi: 10.1016/j.proeng.2011.03.018.

[12] A. Erwin and E. Putra, "Produksi Bahan Bakar Gas Melalui Dekomposisi Bioetanol," no. Snttm Xiii, pp. 1516, 2014.

[13] A. E. E. Putra, S. Nomura, S. Mukasa, and H. Toyota, "Hydrogen production by radio frequency plasma stimulation in methane hydrate at atmospheric pressure," Int. J. Hydrogen Energy, vol. 37, no. 21, pp. 1600016005, 2012, doi: 10.1016/j.ijhydene.2012.07.099.

[14] Sanyo, INSTRUCTION MANUAL EM-S105AW / AS. .

[15] M. R. Hidayat, M. H. Zamzam, and S. U. Prini, "Excitation Analysis of Transverse Electric Mode Rectangular Waveguide," J. Elektron. dan Telekomun., vol. 20, no. 1, p. 1, 2020, doi: 10.14203/jet.v20.1-8.

[16] S. Horikoshi and N. Serpone, "In-liquid plasma: A novel tool in the fabrication of nanomaterials and in the treatment of wastewaters," RSC Adv., vol. 7, no. 75, pp. 47196-47218, 2017, doi: 10.1039/c7ra09600c.

[17] S. Horikoshi, S. Sawada, S. Sato, and N. Serpone, "Microwave-Driven In-liquid Plasma in Chemical and Environmental Applications. III. Examination of Optimum Microwave Pulse Conditions for Prolongation of Electrode Lifetime, and Application to Dye-Contaminated Wastewater," Plasma Chem. Plasma Process., vol. 39, no. 1, pp. 51-62, 2019, doi: 10.1007/s11090-018-9935-x. 